\title{
Tea maker's asthma
}

\author{
C. G. URAGODA \\ The Chest Clinic, Kandy, Ceylon
}

\begin{abstract}
Uragoda, C. G. (1970). Brit. J. industr. Med., 27, 181-182. Tea maker's asthma. In the manufacture of tea, which is supervised by a tea maker, a fine dust called tea fluff is discharged into the atmosphere of the factory. A case of asthma, occurring in a tea maker as the result of inhalation of this fluff, is described. Provocative inhalation of the fluff produced an attack within a few minutes. A positive reaction was obtained on skin testing with tea fluff antigen.

Tea factory cough and tea taster's disease are two other occupational diseases associated with the tea industry.
\end{abstract}

Asthma of occupational origin is known to occur among certain categories of workers. It is mostly seen in trades where workers are exposed to vegetable dusts, including pollen and fungus spores. Dust from gum acacia, wood, grain, tobacco and cotton may cause asthma (Hunter, 1962). In platinum asthma, the aetiological agent is potassium chloroplatinate used in photographic work. As far as could be ascertained, asthma as a result of inhalation of tea dust has not previously been reported.

Ceylon is the world's largest exporter of tea. Tea is grown on estates, especially in the central hilly region of the island. An average-sized tea estate is about a thousand acres in extent and has its own tea factory where the green leaves are processed.

The tea plant, when allowed to grow uninhibited, reaches the height of a medium-sized tree, but on estates regular pruning and plucking of tender shoots restrict its size to a bush. Plucking is done by hand every seven or eight days, and the green leaves are then brought to the factory for manufacture.

The leaves are first withered by blowing warm air over the leaves, which are spread on jute tats, or shelves, arranged in tiers. The withered leaves are then fed into a series of rollers which break them into small pieces. These particles are sifted, and the product known as dhools is spread on trays and allowed to ferment. It is then passed through a drier. The tea, which is black at this stage, is separated into different grades by passage through a series of mechanical sifters having sieves of varying sizes. During the process a fine brownish dust, known as tea fluff, is discharged into the atmosphere of the sifting room. Large exhaust fans which are fitted into the walls of the sifting room are only partially efficient in removing the fluff, and the residual dust settles on the workers as well as on the floor.

The tea is now ready for packing but may be stored for three to five days till a sufficient quantity is collected for the purpose. Some fluff may be given out during packing, though to a lesser extent.

The process of tea manufacture is supervised by a man known as the tea maker. Large factories may employ one or two assistants as well.

The following case report is of a tea maker who developed asthma as the result of inhalation of tea fluff.

\section{Case report}

U.B.S., a 49-year old man, was first seen at the Chest Clinic, Kandy in June 1969. He had worked as a tea maker for 30 years, of which the past 25 years had been served in the same tea factory. This has been his sole occupation in life.

He experienced his first symptoms 15 years before, when he suffered from attacks of sneezing with watering of the 
nose. These episodes used to occur on misty mornings or when he was exposed to rainy weather in the night.

His present symptoms appeared seven years ago. Within a few minutes of entering the sifting or packing rooms, the atmosphere of which was rich in fluff, he developed an attack of asthma. These attacks have followed the same pattern always, but during the past five years they have been gradually getting more severe, so much so that he is now contemplating retirement, though normally he would be entitled to work until the age of 60 years. He gets similar attacks when he visits tea factories elsewhere, but dusts other than fluff do not provoke symptoms. The symptoms are so severe during an attack that he is forced to leave the factory, when they usually subside within $\mathbf{3 0}$ minutes. $\mathrm{He}$ is free of symptoms as long as he keeps away from the factory.

There is no family history of allergic manifestations.

Abnormal physical signs were absent when he was examined during an asymptomatic phase.

The total white cell count was $6600 / \mathrm{mm}^{3}$, of which polymorphs were $58 \%$, lymphocytes $38 \%$ and eosinophils $4 \%$. Radiography of the chest did not show any abnormality. A positive reaction of the immediate type was obtained on skin testing with tea fluff antigen. Culture of the tea fluff showed growths of Aspergillus, Penicillium and Chromobacteria.

He was given a provocative inhalation of tea fluff. After five minutes he complained of irritation of the throat, followed by blocking of the nose and a watery nasal discharge which rapidly became profuse. His breathing became laboured and he began to sweat. He developed a cough which was dry at first, but it quickly became productive of copious quantities of mucoid sputum. Finally, a wheeze appeared which was accompanied by bilateral rhonchi and crepitations. The attack was fully developed 10 minutes after starting the inhalations. Gradually the symptoms subsided.

\section{Discussion}

The only previous reference to an occupational disease among tea workers was that of Castellani and Chalmers (1919). They described two related conditions in Ceylon, which they called tea factory cough and tea taster's disease. The former condition affected labourers working in tea factories. They suffered from loss of weight, tiredness and cough with mucopurulent expectoration. Occasional coarse rales could be heard on auscultation. If these labourers were taken from the factory and sent to work on the field, the symptoms slowly disappeared.

Tea tasters also had a similar affection. In order to judge the quality of tea, the tea tasters, according to Castellani and Chalmers, not only tasted the infusions but also buried their noses in the leaves. In this way the dust, including micro-organisms in it, was inhaled. They found that tea dust, which is a grade of tea consisting of particles larger than those of fluff, contained fungi such as Monilia, Aspergillus and Penicillium as well as a 'peculiar Streptococcus'.

These two conditions are clinically different from the case of asthma described here. The features of the latter are strikingly similar to those of platinum asthma in which, on exposure to complex platinum salts, there is repeated sneezing with profuse watery discharge from the nose followed by tightening of the chest, shortness of breath and wheezing. The symptoms persist for as long as the worker remains in the factory, and subside half an hour after he has left the premises (Perry and Holmes Sellors, 1963).

In this patient the immediate response to provocative inhalation of the allergen, and the positive reaction on skin testing with the fluff antigen, suggest hypersensitivity to tea fluff.

I wish to thank Dr. S. D. de Silva, general practitioner, Kandy for referring this patient to me, and Dr. M. R. M. Pinto, of the Department of Bacteriology, University of Ceylon, Peradeniya, for his assistance in the bacteriological investigation. I should also like to thank Professor J. Pepys, of the Institute of Diseases of the Chest, Brompton Hospital, London, for supplying the tea fluff antigen.

\section{References}

Castellani, A., and Chalmers, A. J. (1919). Manual of Tropical Medicine, 3rd ed. p. 1890 Baillière, Tindall and Cox, London.

Hunter, D. (1962). The Diseases of Occupations, 3rd ed., p. 1001-1025. English Universities Press, London.

Perry, K. M. A., and Sellors, T. Holmes, ed. (1963). Chest Diseases, vol. 1, p. 522. Butterworths, London.

Received for publication October 23, 1969. 